Paediatr Respir Rev. 2010 September ; 11(3): 177-184. doi:10.1016/j.prrv.2010.05.003.

\title{
Early Eradication of Pseudomonas aeruginosa in Patients with Cystic Fibrosis
}

\author{
Bridget Stuart ${ }^{1}$, Jenny H. Lin ${ }^{1}$, and Peter J. Mogayzel Jr. ${ }^{*}$ \\ Eudowood Division of Pediatric Respiratory Sciences, The Johns Hopkins Medical Institutions, \\ Baltimore, Maryland 21287
}

\begin{abstract}
Pseudomonas aeruginosa $(\mathrm{Pa})$ is the predominant organism infecting the airways of patients with cystic fibrosis (CF). This organism has an armamentarium of survival mechanisms that allows it to survive in the CF airway. Since colonization and chronic infection with $\mathrm{Pa}$ is associated with poorer lung function and increased morbidity and mortality, therapies that can prevent infection could significantly improve the lives of patients with CF. Numerous studies have examined the effects of treatment on the eradication of $\mathrm{Pa}$ as a means to ameliorate disease. This article outlines the pathophysiology and clinical implication of $\mathrm{Pa}$ acquisition, and reviews the existing treatment regimens aimed at early eradication of $\mathrm{Pa}$ in patients with $\mathrm{CF}$.
\end{abstract}

\section{Keywords}

Pseudomonas aeruginosa; cystic fibrosis; inhaled tobramycin; eradication therapy; colonization

\section{INTRODUCTION}

Cystic fibrosis (CF) is an autosomal recessive disorder of chloride transport that occurs in approximately 1 in 3,200 Caucasian individuals. Since the first detailed description of CF in 1938 by Dorothy Andersen, much has been elucidated regarding this disease. ${ }^{1}$ The subsequent discovery of disease causing mutations in the cystic fibrosis transmembrane conductance regulator (CFTR) gene in 1989 ushered in a revolution in the understanding of the pathophysiology of CF. ${ }^{2}$ However, our understanding of the interplay between the chloride transport defect in CF airway epithelium and development of chronic bacterial infection is limited.

Although CF affects many organ systems, patients with CF experience the most morbidity and mortality from manifestations of obstructive pulmonary disease. Although a myriad of organisms have been implicated in disease progression, Pseudomonas aeruginosa $(\mathrm{Pa})$ is the predominant organism infecting the airways of patients with CF. This organism is thought to be a significant cause of respiratory complications. Once the airways of CF patients become

\footnotetext{
(C) 2010 Elsevier Ltd. All rights reserved.

*Corresponding author. Eudowood Division of Pediatric Respiratory Sciences, Johns Hopkins Hospital, 600 North Wolfe Street, Park 316, Baltimore, MD 21287-2533. Tel.: +410 955 2795; fax: +410 955 1030. pmogayze@jhmi.edu (P.J. Mogayzel Jr.).

${ }^{1}$ These two authors contributed equally to this work.
} 
colonized, Pa cannot be eradicated. Therefore, any therapy that delays the colonization of $\mathrm{CF}$ airways with $\mathrm{Pa}$ has the potential to preserve lung function. It is hypothesized that patients with CF become transiently infected with Pa before they become colonized with this organism, thereby providing a window of opportunity to eradicate this organism before it gains a foothold towards colonization (Figure 1) ${ }^{3}$. Hence, numerous studies have examined approaches to eradication of early $\mathrm{Pa}$ infection as a means to ameliorate disease. Here, we discuss the pathophysiology and clinical implication of $\mathrm{Pa}$ acquisition, and review the existing treatment regimens aimed at early eradication of $\mathrm{Pa}$ in patients with $\mathrm{CF}$.

\section{PSEUDOMONAS AERUGINOSA IN CYSTIC FIBROSIS}

The interaction between an individual CF patient's lung environment and immune response and the invading bacteria's defence mechanisms determines if the airway will become colonized with $\mathrm{Pa}$. In a normal, healthy lung, inhaled bacteria are cleared through a combination of mechanical and immunological defence mechanisms. In CF, the defective CFTR results in impaired chloride secretion and hyperabsorption of sodium, thereby leading to a dehydrated airway surface liquid layer. ${ }^{4}$ This environment allows bacteria to flourish, as the diseased airway is depleted of surface fluid and thick mucus is retained leading to impaired mucociliary clearance. Additionally, the activity of antimicrobial peptides, which are important in innate immunity, is altered in the CF airway. ${ }^{5}$ The role of CFTR in clearance of $\mathrm{Pa}$ from the airway remains obscure. However, it is known that epithelial cells expressing the CFTR F508del allele demonstrate less uptake and ingestion of $\mathrm{Pa} .{ }^{6}$ While neutrophils, the predominant cell type in CF airways, are involved in fighting off infection, they also play an important role in the inflammatory process. Neutrophils in the CF airway have been shown to have increased adherence and subsequently increase interleukin- 6 and interleukin-8 levels which contribute to prolonged inflammation. ${ }^{7,8}$

In addition to having a suitable growing environment, $\mathrm{Pa}$ is a resourceful organism that has evolved multiple mechanisms to enhance its survival in the CF airway. Initially, Pa uses flagella to navigate and pili to adhere to respiratory epithelium. ${ }^{9}$ Once infection has been established, Pa utilizes several mechanisms to evade the host immune system. Pa secretes many products to aid in its survival including: elastase (ELA) and alkaline protease (AP) that cleave immunoglobulins, cytokines, and complement; exotoxin A (ExoA) that inhibits phagocytosis; and pyocyanin that impairs mucociliary clearance by slowing ciliary beat frequency. ${ }^{10} \mathrm{P}$. aeruginosa has also been shown to downregulate the transcription of flagellin, an important inducer of pro-inflammatory markers such as interleukin- 8 and stimulator of the host immune response via Toll-like receptor 5, after colonization. ${ }^{11,12}$ As $\mathrm{Pa}$ is exposed to various antimicrobials over time, it accumulates mutations that help establish chronic infection and convey antibiotic resistance. Among these mutations is the loss of function mutation in mucA, a negative regulator of exopolysaccharide alginate production. The resulting increased alginate production is thought to confer additional protection for Pa against host defences such as mucociliary clearance and antimicrobial penetration, and it has been associated with an attenuated inflammatory response. ${ }^{12}$ The production of alginate gives $\mathrm{Pa}$ a mucoid phenotype when grown in vitro. 
Finally, biofilm formation represents another important survival mechanism that allows $\mathrm{Pa}$ to establish chronicity in the $\mathrm{CF}$ airway. Studies show that Pa colonies attach, form, and expand into structured communities of bacteria surrounded by a polymeric matrix within the thick mucus of the respiratory airway. ${ }^{13,14}$ P. aeruginosa growing in a biofilm are rendered more difficult to remove by mucociliary clearance, and develop increased antibiotic resistance. ${ }^{15,16}$ Biofilm formation is preceded by bacterial attachment and multiplication on the lung epithelium. Once a certain bacterial density is reached and growth slows, biofilm production is signalled by a process of quorum sensing, in which extracellular signals herald the differentiation of Pa bacterial cells into complex multicellular structures. ${ }^{13,14}$

\section{DETECTION OF PSEUDOMONAS AERUGINOSA}

Identifying initial $\mathrm{Pa}$ infection is challenging since it often occurs in young patients who cannot expectorate sputum. Several methods are employed to detect the presence of $\mathrm{Pa}$ in the lower respiratory tract. However, no gold standard exists for diagnosis, as each technique has its advantages and disadvantages. Ideally, lower respiratory tract Pa would be detected by bronchoscopy with bronchoalveolar lavage (BAL); however, this procedure is invasive and requires deep sedation or general anaesthesia. Sputum induction is used in older children and adults, due to ease of procurement and accurate representation of organisms in the lower respiratory tract. However, young children are frequently unable to coordinate sputum expectoration, even with the aid of hypertonic saline. Thus, in this population, oropharyngeal (OP) cultures are the mainstay for diagnosis of Pa infection in clinical practice.

The usefulness of OP cultures to identify Pa in the lower respiratory tract has been examined, comparing OP culture results to those from simultaneous BAL (Table 1). ${ }^{17-20}$ Ramsey and colleagues initially concluded that positive OP cultures are highly predictive of lower airway disease. ${ }^{20}$ In three subsequent studies, however, negative OP cultures were found to more reliably predict absence of infection. ${ }^{17-19}$ Culture results from OP swabs must, therefore, be interpreted carefully. Despite their limitations, results from OP cultures in patients unable to yield adequate induced sputum samples are used by many clinicians as a surrogate marker for detection of $\mathrm{Pa}$ in the lower respiratory tract.

The use of serologic markers of the immune response to Pa antigens has also been proposed as a method to detect Pa colonization. Several techniques, including crossed immunoelectrophoresis, radioimmunoassay (RIA), and enzyme-linked immunosorbent assay (ELISA) have been utilized. ${ }^{21}$ Several studies demonstrate the presence of anti-Pa antibody titres may help distinguish early infection from chronic colonization. In a 1987 prospective study of 62 patients, increasing anti-Pa titres were found only in patients who developed chronic Pa colonization. Elevated titres against phospholipase C (PLC) were found in 100\% of patients with chronic Pa colonization, while 58\% had increased titres to AP and ExoA. Titres against ELA were higher in $15 \%$ of Pa colonized patients. ${ }^{22,23}$ Furthermore, anti-Pa antibodies have the potential to reveal the presence of $\mathrm{Pa}$ infection before the bacteria are obtained by culture. In a study of 33 patients in Leeds, UK, 24 patients demonstrated increasing $\mathrm{IgG}$ titres against $\mathrm{Pa}$ as early as 2 years before initial isolation of the organism. ${ }^{24}$ Similarly, Danish investigators found that increasing anti-Pa IgG titres were detectable up to 
3 years prior to infection. ${ }^{25}$ Though not yet widely used, molecular techniques such as PCR are highly sensitive for detecting Pa (93-100\%). ${ }^{26-29}$ Indeed, the combination of serologic markers with PCR evidence of infection can successfully identify more patients with chronic Pa colonization than serology, sputum or nasopharyngeal culture, or PCR alone, according to a 2007 study. ${ }^{23}$

\section{CLASSIFYING PSEUDOMONAS AERUGINOSA "INFECTION"}

Organisms that predominate in the respiratory tract vary with time. Early in CF airway infection, Staphylococcus aureus and Haemophilus influenza predominate. P. aeruginosa becomes a main culprit later in life, with a mean age of acquisition of 45 months. ${ }^{30} \mathrm{~A}$ prospective, longitudinal cohort study of infants enrolled at 3 American CF centres showed that over $97 \%$ of the patients had serologic or microbiologic evidence of Pa infection by age $3 .{ }^{17}$ Female sex, homozygosity for the F508del mutation, and continuous therapy with antistaphylococcal antibiotics are among the risk factors for early acquisition of $\mathrm{Pa}^{3}{ }^{31,32}$ The prevalence of Pa infection steadily increases with advancing age. Data from the $\mathrm{CF}$ Foundation Patient Registry demonstrate that as many as $20-25 \%$ of infants and $25-50 \%$ of children age 2-10 years have had Pa obtained from at least one airway culture. According to the 2008 CF Foundation Patient Registry, the shift to $\mathrm{Pa}$ as the predominant organism occurs between ages 25-34 years in the United States. Approximately three-quarters of adults with $\mathrm{CF}$ and one-third of children with CF had cultures which grew Pa. This peak incidence occurs at a later age than what has been reported in previous years. ${ }^{33}$

Precise classification of Pa infection remains problematic. The timeline of harbouring Pa can be regarded in terms of initial acquisition of the organism, early intermittent infection, and chronic infection (Figure 1). In published work, the terms "colonization" and "early infection" are sometimes used interchangeably when describing the presence of Pa in the respiratory tract. The first definition of chronic infection introduced in 1974 by Professor Høiby in the Copenhagen CF centre was based on monthly microbiological examination of sputum and was later modified to include the antibody response to Pa. ${ }^{34,35}$ Many centres do not obtain monthly microbiology samples nor do they measure Pa serologies; thus, in 2000, a European Consensus Committee convened by the European CF Society published a consensus definition for chronic infection. ${ }^{21}$ Perhaps the most comprehensive criteria to date for categorizing Pa infection comes from Leeds, UK, where airway cultures from a 12 month period were evaluated and used to group patients into four categories (Table 2). ${ }^{36}$ Despite these efforts, no universal definition of chronic infection has been widely accepted, a factor that may complicate early treatment recommendations.

\section{CLINICAL IMPLICATIONS}

The significance of early detection and the rationale behind early eradication of $\mathrm{Pa}$ has important implications on clinical outcomes in children with CF. Early colonization with $\mathrm{Pa}$ has been associated with poorer lung function, lower weight percentiles, and increased morbidity and mortality. ${ }^{37-40}$ In one particular prospective, observational cohort study involving 56 children, infection with Pa resulted in lower average $\mathrm{FEV}^{1}$ values, worse disease severity as measured by NIH scores and prolonged hospitalization stays for 
respiratory illness. Furthermore, all of the patients who died in this study had acquired a multi-resistant, mucoid strain of $\mathrm{Pa}^{30}$ The production of alginate as a mechanism for evading the host immune system gives Pa "mucoid" phenotype, which is associated with chronic infection, antibiotic resistance, and more rapid decline in lung function. Studies have suggested that the conversion from the non-mucoid to the mucoid phenotype occurs over a relatively short time period of about 1.8 years. ${ }^{30,41}$ These findings clearly indicate that early detection and early eradication of Pa can have important implications for clinical outcomes in children with $\mathrm{CF}$.

\section{ERADICATION OF PSEUDOMONAS AERUGINOSA}

\section{Studies Support Benefit of Early Therapy}

Studies dating back to the 1980's have investigated the effects of early treatment for patients known to harbour $\mathrm{Pa}$ (Table 3). Several investigators have addressed the hypothesis that early eradication of $\mathrm{Pa}$ may lead to decreased number of patients with chronic $\mathrm{Pa}$ colonization. Table 3 summarizes the results from many of these studies, emphasizing the anti-pseudomonal regimen employed and the efficacy of Pa eradication. Caution must be taken when comparing these studies, as the method of Pa detection and definitions of infection and chronic colonization are not consistent between reports. Despite these differences, when taken together, this evidence supports the use of early therapy to prevent chronic colonization with $\mathrm{Pa}$. Still, the best regimen(s) remains to be determined. An optimal treatment plan would be one that is well-tolerated with few side effects, shows maximal effectiveness in eradicating $\mathrm{Pa}$ as well as maintaining eradication, and would be based on results from a large study group, ideally, from a randomized, controlled trial.

The concept of early eradication was first reported by Little-wood et al who noted decreased frequency of cultures with Pa growth after initiation of colistin in a case study of 7 patients. ${ }^{42}$ The first published randomized, controlled trial performed by Valerius et al in 1991 showed in patients treated with inhaled colisitin and oral ciprofloxacin, 86\% remained free of chronic colonization versus $42 \%$ of untreated patients (at mean follow up time of 17.4 months). ${ }^{43}$ These authors specifically evaluated time to chronic colonization rather than elimination of $\mathrm{Pa}$ after treatment. They rigorously defined chronic colonization as $\mathrm{Pa}$ growth in monthly sputum cultures for 6 consecutive months and/or precipitating antibodies against $\mathrm{Pa}^{21}$ Other groups report similar findings comparing inhaled anti-pseudomonal antibiotics and oral fluoroquinolones with historic controls. ${ }^{44,45}$

The next reported randomized, controlled study published in 1998 evaluated the efficacy of inhaled tobramycin for one year by a "time to event" analysis, looking for conversion to cultures without $\mathrm{Pa} .{ }^{46}$ The authors acknowledge the weakness of the study, largely secondary to patient dropout rate; still, $88 \%$ of treated patients cleared Pa from their cultures, while none of the 4 patients completing placebo treatment successfully cleared the infection. Ratjen et al also evaluated this regimen in an open label, uncontrolled study and found that $93 \%$ of patients successfully eradicated $\mathrm{Pa}$ and the same number remained culture and precipitin antibody-negative at one year of follow up ${ }^{47}$. Sixty percent of patients treated were still culture and antibody negative after 2 years. In 2003, Gibson et al randomized 21 patients to inhaled tobramycin or placebo therapy and determined eradication rates in the 
two groups based on cultures from bronchoalveolar lavage. ${ }^{48,49}$ They found that Pa was cleared from $100 \%$ of the treatment group, compared to only $7 \%$ of the controls. Seventyfive percent of those treated continued to be free of Pa two months later. Indeed, this trial was stopped early due to the significant microbiological effect revealed in the treatment group. These investigators expanded the duration of inhaled tobramycin to 28 or 56 days and found that $75 \%$ of patients treated for 28 days and $82 \%$ of patients treated for 56 days had no Pa growth in BAL cultures at 112 days. ${ }^{49}$ Further, they showed inhaled tobramycin had a more robust antimicrobial effect on lower airway Pa by comparing cultures from oropharyngeal samples with those taken from BAL.

Perhaps the most thoroughly evaluated treatment combines inhaled and oral antipseudomonal therapies, first described by Valerius, as discussed above. ${ }^{43}$ Several groups report the efficacy of this regimen by different outcome measures, mostly in studies using historical controls. ${ }^{44,45,50,51}$ Vazquez et al found significantly fewer cultures with Pa growth $(\mathrm{p}<0.001)$ from patients treated with inhaled colistin and tobramycin plus oral ciprofloxacin for 14 days. ${ }^{44}$ Frederiksen and colleagues evaluated a group three times the size of the Valerius study by the same outcome measure: time to chronic colonization. ${ }^{45}$ Using the same definition of chronic colonization, they found $84 \%$ of patients treated with inhaled colisitin and oral ciprofloxacin were not chronically colonized at 3.5 years compared with $28 \%$ of historical controls. Additional studies showed $81 \%$ (median) of treated patients continued to have cultures free of Pa for 18 months after initial eradication. ${ }^{50}$ Indeed, in the $51 \%$ of patients recolonised during this study's 7 year follow-up period, genotypically novel Pa strains were identified in $73 \%$ of cases, providing evidence of eradication with subsequent infection with a genetically different organism. Most recently in 2008, Hansen et al showed treatment with inhaled colistin and oral ciprofloxacin for 3 weeks or 3 months led to longer duration until $\mathrm{Pa}$ acquisition: 5 months in the 3 week group and 10.4 months in the 3 month group (not statistically different from those treated for 3 weeks) compared to 1.9 months in the untreated group (statistically significant difference from the treated groups). ${ }^{51}$ These patients were also evaluated for development of chronic infection, according to criteria from both Copenhagen and Leeds. Anti-pseudomonal therapy delayed time to chronic infection to 3.7 years in 12 of the 99 patients who were treated. Eighty percent of all treated patients were protected from chronicity up to 15 years. Though time to chronic infection varied a few years depending on the definition used, all 12 patients ultimately met criteria from both Copenhagen and Leeds, demonstrating good agreement between the definitions of chronicity from the two centres.

A recent article from the Cochrane Database of Systematic Reviews addressed the issue of antibiotic therapy for eradication of $\mathrm{Pa}$ in patients with $\mathrm{CF} .{ }^{52}$ The authors included randomized, controlled trials evaluating combinations of inhaled, oral or intravenous antibiotics versus placebo, usual treatment, or other combinations of inhaled, oral or intravenous antibiotics. Twenty-five studies were initially identified; four met inclusion criteria and were conducted in paediatric patients only. The authors concluded inhaled antibiotics, alone or in combination with oral antibiotics, successfully eliminated Pa from CF patients more often than no treatment. Further, they noted some lasting effect of the antibiotic treatment in maintaining eradication. Even with this systematic evaluation, 
however, they were unable to determine the best regimen for $\mathrm{Pa}$ eradication based on the published data available.

\section{Studies Underway-Any Treatment Guideline in Sight?}

Several large, randomized, multicenter trials are currently underway to further evaluate widely used anti-pseudomonal regimens (Table 4). The European ELITE study assigned patients to 28 or 56 days of inhaled tobramycin, with a follow up period of 27 months. ${ }^{53}$ Preliminary reports show no significant benefit to continuing therapy beyond the 28 day period, with both groups showing approximately $90 \%$ eradication of $\mathrm{Pa}$ after one month of treatment. In the United States, investigators are comparing cyclic anti-pseudomonal treatment with culture-based therapy in the EPIC study ${ }^{54}$ Three hundred and six patients were enrolled and treated upon first acquisition of Pa. Subsequent treatment was either scheduled quarterly or based on results from respiratory cultures taken every 3 months. To examine the benefit of additional oral anti-pseudomonal therapy, each group was further randomized to receive oral ciprofloxacin or placebo in addition to inhaled tobramycin. Preliminary results presented at the North American CF Conference in October, 2009 suggested that all the approaches to Pa eradication were effective. However, the preventative approach did not appear to be more effective than culture-based therapy. Furthermore, the addition of ciprofloxacin did not confer additional benefit over inhaled tobramycin alone (www.cff.org). Another smaller study underway in Belgium randomized patients with newly isolated $\mathrm{Pa}$ (from sputum or cough swabs) to treatment with either inhaled tobramycin or inhaled colistin plus oral ciprofloxacin. ${ }^{55}$ Early analysis has shown that both regimens have comparable rates of immediate and lasting Pa eradication, though only half of patients treated in either arm remain free of $\mathrm{Pa}$ at 6 months without additional antibiotic treatment. Finally, 168 infants diagnosed with CF by newborn screening in Australia and New Zealand were recruited to a 5 year prospective, randomized trial of BAL-directed therapy. ${ }^{56}$ Patients in one arm of the trial were treated based on clinical symptoms and results of cough suction specimens while therapy for the other arm was based on BAL results from routine bronchoscopy or BAL performed during exacerbations. Treatment consisted of IV therapy, followed by inhaled and oral anti-pseudomonal medications. In patients followed for two years thus far, $100 \%$ have successfully eradicated Pa in both groups, bolstering the evidence for Pa infection early in life and the ability to successfully eradicate the organism when diagnosed.

For early eradication of Pa, the utility and efficacy of inhaled colisitin or tobramycin have clearly been demonstrated. Parenteral antibiotics may be beneficial as additional therapy, as their use alone has resulted in Pa elimination in some studies. ${ }^{57}$ Results from the ELITE and EPIC trials will be valuable in refining an early eradication regimen for patients with $\mathrm{Pa}$. Specifically, duration of treatment and the usefulness of oral antibiotics may be readily ascertained once these studies are complete. We eagerly await the results of these trials for further treatment recommendations.

\section{A Note about Drug Delivery}

While the benefit of inhaled antibiotic therapy for Pa eradication is clear, treatment guidelines must also account for mode of delivery of these medications, recently reviewed 
by Kesser and Geller. ${ }^{58}$ The use of nebulised drugs presents multiple challenges to patients with $\mathrm{CF}$ and the clinicians caring for them. First, the drug-containing particles must be of an appropriate size to reach the target destination in the lung. This issue is particularly challenging in young children, who have small calibre airways and small tidal volumes and are limited to tidal breathing and mask interfaces. ${ }^{59,60}$ Medication administration time also presents a difficulty for patients striving to be compliant with multiple therapies. Nebulisers that deliver therapy more quickly are available and have already been used with some CF therapies, including vibrating-mesh nebulisers such as the eFlow (PARI Pharma) and the Aerogen AeroNebGo (Nektar Therapeutics, now part of Novartis). Nebulisers must be cleaned and sterilised on a regular basis to ensure accurate drug delivery, another factor adding to the already time-intensive daily schedule of CF patients. Portable, low maintenance models that deliver medication quickly are currently under development to facilitate patient adherence to treatment.

Ensuring accurate dosing of inhaled antibiotics is perhaps the most concerning aspect of nebuliser use for Pa eradication. Initial pharmacokinetic (PK) studies performed on sputum from patients using the UltraNeb 100 (DeVilbiss) ultrasonic nebuliser showed tobramycin was delivered well with this machine. ${ }^{61}$ Follow up studies using the LC Plus (PARI Pharma) jet nebuliser showed the same high sputum levels of tobramycin could be achieved with half the nominal dose, indicating that drug dosing is device-specific. ${ }^{62-64} \mathrm{New}$ nebulisers have been designed to deliver medication with decreased residual volumes, resulting in more complete dose delivery. The eFlow is one such model, though a second eFlow version (eFlow Rapid) was designed according to delivery efficiency parameters seen with the use of the PARI LC jet nebuliser. ${ }^{58}$ The eFlow Rapid has a larger residual volume and a smaller aerosol chamber, resulting in more drug loss during exhalation; thus, the two eFlow models cannot be used interchangeably. Other novel nebulisers are designed to control patient breathing during drug delivery to prevent medication waste, including adaptive aerosol delivery systems such as I-neb (Respironics/Philips) and the Akita device (Activaero).

As newer, ultrafast nebulisers enter the market, clinicians must caution patients against indiscriminate use of nebuliser machines for different therapies. In 2008, an expert panel convened by the European CF Society agreed that: "Every drug-device combination should be tested in clinical studies for efficacy and safety, especially for drugs with a small therapeutic window." 65 Indeed, many therapies based on the results of clinical trials are only approved for a specific drug-nebuliser combination. Off-label use of these nebulisers may result in insufficient dosing of the drug as was seen with use of the Sidestream (Respironics) nebuliser to administer inhaled tobramycin; pharmacokinetic studies showed the lung dose of tobramycin was half of that seen with use of the on-label nebuliser the Pari LC Plus. ${ }^{62}$ The off-label use of these machines may also have toxic side effects (e.g., tachyarrhythmia with unit-dose albuterol); thus, care must be exercised and instructions must be specific regarding nebuliser use for control of $\mathrm{Pa}$ in $\mathrm{CF}$ patients.

\section{Future Directions}

Early eradication therapies against $\mathrm{Pa}$ have been shown to be effective based on microbiologic data. How this treatment affects the clinical course of $\mathrm{CF}$, however, remains 
unclear. As early as 1989, Steinkamp et al demonstrated some improvement in weight for height ratio and overall clinical status following eradication therapy. ${ }^{66}$ Those with poor lung function at the beginning of therapy showed significant improvement. Almost a decade later, Frederiksen and colleagues also showed improvement in pulmonary function (FVC and $\mathrm{FEV}^{1}$ ) in patients treated with inhaled colisitin and oral ciprofloxacin. ${ }^{45}$ Conversely, other studies have shown no change in lung function after treatment. ${ }^{46,47}$ In spite of these findings, the association of $\mathrm{Pa}$ chronic infection with worse outcome is wellestablished. ${ }^{67-69}$ Thus, protecting patients with $\mathrm{CF}$ from becoming chronically colonized with $\mathrm{Pa}$ remains a priority to clinicians and researchers alike.

Several alternative strategies are under investigation, including the use of a daily mouthwash containing anti-pseudomonal $\mathrm{IgY}$ and vaccination against $\mathrm{Pa}$ (recently reviewed by Johansen and Gotzsche). ${ }^{70,71}$ Unfortunately, confounding therapy in the Nilsson et al study and the frequency of adverse events in one of the largest vaccination trials have prevented recommendation of these treatment modalities at this time. ${ }^{70,71}$ Other therapies such as nebulised antibodies against $\mathrm{Pa}$, new antibiotic formulations (including liposomal and drypowder inhaled preparations) and more effective delivery devices are under development. Ultimately, preventing chronic colonization of Pa remains an important goal for maintaining quality of life and longevity in patients with CF.

\section{NOTE IN PROOF}

Since submission of this paper, the results of the European ELITE study have been published. ${ }^{72}$ This study was a large, randomized, multicenter trial undertaken to examine the safety and efficacy of 28 or 56 days of inhaled tobramycin in the eradication of Pa. Cystic fibrosis patients 6 months or older were enrolled from November 2003 to January 2008 and given 28 days of inhaled tobramycin solution. At the end of this period, participants were randomized to either stop treatment or continue for an additional 28 days. Recently published results from this trial showed eradication of $\mathrm{Pa}$ (by either deep throat swab or sputum culture) was similar in both groups, with $93 \%$ and $92 \%$ free of $\mathrm{Pa}$ one month after the end of treatment in the 28- and 56-day groups, respectively. ${ }^{72}$ The median time to recurrence was 26.12 and 25.82 months in the 28- and 56-day treatment groups, respectively, not a statistically significant difference. The ELITE trial demonstrates that a 28-day regimen of inhaled tobramycin is effective in treating early Pa infection and extending the treatment to 56 days does not provide any additional benefit. Given the scale of this study, clinicians should consider a shorter course of inhaled tobramycin effective in early eradication of $\mathrm{Pa}$.

\section{Abbreviations}

Pa Pseudomonas aeruginosa

CF cystic fibrosis

CFTR cystic fibrosis transmembrane conductance regulator

BAL bronchoalveolar lavage 
$\begin{array}{ll}\text { OP } & \text { oropharyngeal } \\ \text { PCR } & \text { polymerase chain reaction }\end{array}$

\section{References}

1. Andersen DH. Cystic fibrosis of the pancreas and its relationship to celiac disease: a clinical and pathological study. Am J Dis Child. 1938; 56:344.

2. Kerem B, Rommens JM, Buchanan JA, et al. Identification of the cystic fibrosis gene: genetic analysis. Science. 1989; 245(4922):1073-1080. [PubMed: 2570460]

3. Lee TW. Eradication of early Pseudomonas infection in cystic fibrosis. Chron Respir Dis. 2009; 6(2):99-107. [PubMed: 19411571]

4. Matsui H, Grubb BR, Tarran R, et al. Evidence for periciliary liquid layer depletion, not abnormal ion composition, in the pathogenesis of cystic fibrosis airways disease. Cell. 1998; 95(7):10051015. [PubMed: 9875854]

5. Sagel SD, Sontag MK, Accurso FJ. Relationship between antimicrobial proteins and airway inflammation and infection in cystic fibrosis. Pediatr Pulmonol. 2009; 44(4):402-409. [PubMed: 19283840]

6. Pier GB, Grout M, Zaidi TS, et al. Role of mutant CFTR in hypersusceptibility of cystic fibrosis patients to lung infections. Science. 1996; 271(5245):64-67. [PubMed: 8539601]

7. Downey DG, Bell SC, Elborn JS. Neutrophils in cystic fibrosis. Thorax. 2009; 64(1):81-88. [PubMed: 19103874]

8. Tabary O, Corvol H, Boncoeur E, et al. Adherence of airway neutrophils and inflammatory response are increased in CF airway epithelial cell-neutrophil interactions. Am J Physiol Lung Cell Mol Physiol. 2006; 290(3):L588-L596. [PubMed: 16272177]

9. Tang H, Kays M, Prince A. Role of Pseudomonas aeruginosa pili in acute pulmonary infection. Infect Immun. 1995; 63(4):1278-1285. [PubMed: 7890385]

10. Davies JC, Bilton D. Bugs, biofilms, and resistance in cystic fibrosis. Respir Care. 2009; 54(5): 628-640. [PubMed: 19393107]

11. Hybiske K, Ichikawa JK, Huang V, et al. Cystic fibrosis airway epithelial cell polarity and bacterial flagellin determine host response to Pseudomonas aeruginosa. Cell Microbiol. 2004; 6(1):49-63. [PubMed: 14678330]

12. Cobb LM, Mychaleckyj JC, Wozniak DJ, et al. Pseudomonas aeruginosa flagellin and alginate elicit very distinct gene expression patterns in airway epithelial cells: implications for cystic fibrosis disease. J Immunol. 2004; 173(9):5659-5670. [PubMed: 15494517]

13. Davies DG, Parsek MR, Pearson JP, et al. The involvement of cell-to-cell signals in the development of a bacterial biofilm. Science. 1998; 280(5361):295-298. [PubMed: 9535661]

14. Singh PK, Schaefer AL, Parsek MR, et al. Quorum-sensing signals indicate that cystic fibrosis lungs are infected with bacterial biofilms. Nature. 2000; 407(6805):762-764. [PubMed: 11048725]

15. Landry RM, An D, Hupp JT, et al. Mucin-Pseudomonas aeruginosa interactions promote biofilm formation and antibiotic resistance. Mol Microbiol. 2006; 59(1):142-151. [PubMed: 16359324]

16. Gillis RJ, White KG, Choi KH, et al. Molecular basis of azithromycin-resistant Pseudomonas aeruginosa biofilms. Antimicrob Agents Chemother. 2005; 49(9):3858-3867. [PubMed: 16127063]

17. Burns J, Gibson R, McNamara S, et al. Longitudinal Assessment of Pseudomonas aeruginosa in Young Children with Cystic Fibrosis. The Journal of Infectious Diseases. 2001; 183(3):444-452. [PubMed: 11133376]

18. Armstrong DS, Grimwood K, Carlin JB, et al. Bronchoalveolar lavage or oropharyngeal cultures to identify lower respiratory pathogens in infants with cystic fibrosis. Pediatr Pulmonol. 1996; 21(5): 267-275. [PubMed: 8726151] 
19. Rosenfeld M, Emerson J, Accurso F, et al. Diagnostic accuracy of oropharyngeal cultures in infants and young children with cystic fibrosis. Pediatr Pulmonol. 1999; 28(5):321-328. [PubMed: 10536062]

20. Ramsey BW, Wentz KR, Smith AL, et al. Predictive value of oropharyngeal cultures for identifying lower airway bacteria in cystic fibrosis patients. Am Rev Respir Dis. 1991; 144(2): 331-337. [PubMed: 1859056]

21. Doring G, Conway SP, Heijerman HG, et al. Antibiotic therapy against Pseudomonas aeruginosa in cystic fibrosis: a European consensus. Eur Respir J. 2000; 16(4):749-767. [PubMed: 11106223]

22. Hollsing AE, Granstrom M, Vasil ML, et al. Prospective study of serum antibodies to Pseudomonas aeruginosa exoproteins in cystic fibrosis. J Clin Microbiol. 1987; 25(10):18681874. [PubMed: 3117842]

23. da Silva Filho LV, Tateno AF, Martins KM, et al. The combination of PCR and serology increases the diagnosis of Pseudomonas aeruginosa colonization/infection in cystic fibrosis. Pediatr Pulmonol. 2007; 42(10):938-944. [PubMed: 17722007]

24. Brett MM, Ghoneim AT, Littlewood JM. Prediction and diagnosis of early Pseudomonas aeruginosa infection in cystic fibrosis: a follow-up study. J Clin Microbiol. 1988; 26(8):15651570. [PubMed: 3139707]

25. Pressler T, Frederiksen B, Skov M, et al. Early rise of anti-pseudomonas antibodies and a mucoid phenotype of pseudomonas aeruginosa are risk factors for development of chronic lung infectiona case control study. J Cyst Fibros. 2006; 5(1):9-15. [PubMed: 16412706]

26. Karpati F, Jonasson J. Polymerase chain reaction for the detection of Pseudomonas aeruginosa, Stenotrophomonas maltophilia and Burkholderia cepacia in sputum of patients with cystic fibrosis. Mol Cell Probes. 1996; 10(6):397-403. [PubMed: 9025076]

27. da Silva Filho LV, Tateno AF, Velloso LF, et al. Identification of Pseudomonas aeruginosa, Burkholderia cepacia complex, and Stenotrophomonas maltophilia in respiratory samples from cystic fibrosis patients using multiplex PCR. Pediatr Pulmonol. 2004; 37(6):537-547. [PubMed: 15114555]

28. Xu J, Moore JE, Murphy PG, et al. Early detection of Pseudomonas aeruginosa-comparison of conventional versus molecular (PCR) detection directly from adult patients with cystic fibrosis (CF). Ann Clin Microbiol Antimicrob. 2004; 3:21. [PubMed: 15496232]

29. Spilker T, Coenye T, Vandamme P, et al. PCR-based assay for differentiation of Pseudomonas aeruginosa from other Pseudomonas species recovered from cystic fibrosis patients. J Clin Microbiol. 2004; 42(5):2074-2079. [PubMed: 15131172]

30. Nixon GM, Armstrong DS, Carzino R, et al. Clinical outcome after early Pseudomonas aeruginosa infection in cystic fibrosis. J Pediatr. 2001; 138(5):699-704. [PubMed: 11343046]

31. Maselli JH, Sontag MK, Norris JM, et al. Risk factors for initial acquisition of Pseudomonas aeruginosa in children with cystic fibrosis identified by newborn screening. Pediatr Pulmonol. 2003; 35(4):257-262. [PubMed: 12629621]

32. Ratjen F, Comes G, Paul K, et al. Effect of continuous antistaphylococcal therapy on the rate of P. aeruginosa acquisition in patients with cystic fibrosis. Pediatr Pulmonol. 2001; 31(1):13-16. [PubMed: 11180669]

33. Cystic Fibrosis Foundation: Patient Registry 2008 Annual Report. Bethesda, MD: 2009.

34. Høiby N, Flensborg EW, Beck B, et al. Pseudomonas aeruginosa infection in cystic fibrosis. Diagnostic and prognostic significance of Pseudomonas aeruginosa precipitins determined by means of crossed immunoelectrophoresis. Scand J Respir Dis. 1977; 58(2):65-79. [PubMed: 404701]

35. Høiby N. Pseudomonas aeruginosa infection in cystic fibrosis. Relationship between mucoid strains of Pseudomonas aeruginosa and the humoral immune response. Acta Pathol Microbiol Scand B Microbiol Immunol. 1974; 82(4):551-558. [PubMed: 4213330]

36. Lee TW, Brownlee KG, Conway SP, et al. Evaluation of a new definition for chronic Pseudomonas aeruginosa infection in cystic fibrosis patients. J Cyst Fibros. 2003; 2(1):29-34. [PubMed: 15463843]

37. Schaedel C, de MI, Hjelte L, et al. Predictors of deterioration of lung function in cystic fibrosis. Pediatr Pulmonol. 2002; 33(6):483-491. [PubMed: 12001283] 
38. Parad RB, Gerard CJ, Zurakowski D, et al. Pulmonary outcome in cystic fibrosis is influenced primarily by mucoid Pseudomonas aeruginosa infection and immune status and only modestly by genotype. Infect Immun. 1999; 67(9):4744-4750. [PubMed: 10456926]

39. Aebi C, Bracher R, Liechti-Gallati S, et al. The age at onset of chronic Pseudomonas aeruginosa colonization in cystic fibrosis-prognostic significance. Eur J Pediatr. 1995; 154 Suppl 4(9):S69 S73. [PubMed: 8529715]

40. Emerson J, Rosenfeld M, McNamara S, et al. Pseudomonas aeruginosa and other predictors of mortality and morbidity in young children with cystic fibrosis. Pediatr Pulmonol. 2002; 34(2):91100. [PubMed: 12112774]

41. Ballmann M, Rabsch P, von der HH. Long-term follow up of changes in $\mathrm{FEV}^{1}$ and treatment intensity during Pseudomonas aeruginosa colonisation in patients with cystic fibrosis. Thorax. 1998; 53(9):732-737. [PubMed: 10319054]

42. Littlewood JM, Miller MG, Ghoneim AT, et al. Nebulised colomycin for early pseudomonas colonisation in cystic fibrosis. Lancet. 1985; 1(8433):865. [PubMed: 2858720]

43. Valerius NH, Koch C, Høiby N. Prevention of chronic Pseudomonas aeruginosa colonisation in cystic fibrosis by early treatment. Lancet. 1991; 338(8769):725-726. [PubMed: 1679870]

44. Vazquez C, Municio M, Corera M, et al. Early treatment of Pseudomonas aeruginosa colonization in cystic fibrosis. Acta Paediatr. 1993; 82(3):308-309. [PubMed: 8495091]

45. Frederiksen B, Koch C, Høiby N. Antibiotic treatment of initial colonization with Pseudomonas aeruginosa postpones chronic infection and prevents deterioration of pulmonary function in cystic fibrosis. Pediatr Pulmonol. 1997; 23(5):330-335. [PubMed: 9168506]

46. Wiesemann HG, Steinkamp G, Ratjen F, et al. Placebo-controlled, double-blind, randomized study of aerosolized tobramycin for early treatment of Pseudomonas aeruginosa colonization in cystic fibrosis. Pediatr Pulmonol. 1998; 25(2):88-92. [PubMed: 9516091]

47. Ratjen F, Doring G, Nikolaizik WH. Effect of inhaled tobramycin on early Pseudomonas aeruginosa colonisation in patients with cystic fibrosis. Lancet. 2001; 358(9286):983-984. [PubMed: 11583754]

48. Gibson RL, Emerson J, McNamara S, et al. Significant microbiological effect of inhaled tobramycin in young children with cystic fibrosis. Am J Respir Crit Care Med. 2003; 167(6):841849. [PubMed: 12480612]

49. Gibson RL, Emerson J, Mayer-Hamblett N, et al. Duration of treatment effect after tobramycin solution for inhalation in young children with cystic fibrosis. Pediatr Pulmonol. 2007; 42(7):610623. [PubMed: 17534969]

50. Taccetti G, Campana S, Festini F, et al. Early eradication therapy against Pseudomonas aeruginosa in cystic fibrosis patients. Eur Respir J. 2005; 26(3):458-461. [PubMed: 16135728]

51. Hansen CR, Pressler T, Høiby N. Early aggressive eradication therapy for intermittent Pseudomonas aeruginosa airway colonization in cystic fibrosis patients: 15 years experience. $\mathrm{J}$ Cyst Fibros. 2008; 7(6):523-530. [PubMed: 18693078]

52. Langton Hewer SC, Smyth AR. Antibiotic strategies for eradicating Pseudomonas aeruginosa in people with cystic fibrosis. Cochrane Database Syst Rev. 2009; 4:CD004197. [PubMed: 19821321]

53. Ratjen R, Stenglein S, Munck A. Inhaled tobramycin nebulizer solution for treatment of early Pseudomonas aeruginosa infection: the ELITE study. J Cyst Fibros. 2008; 7(Suppl 2):S26.

54. Treggiari MM, Rosenfeld M, Mayer-Hamblett N, et al. Early Anti-Pseudomonal Acquisition in Young Patients with Cystic Fibrosis: Rationale and Design of the EPIC Clinical Trial and Observational Study. Contemp Clin Trials. 2009

55. Proesmans M, Boulanger L, Vermeulen F, et al. Eradication of Recent Pseudomonas aeruginosa isolation: TOBI versus colisitin/ciprofloxacin. Pediatr Pulmonol. 2009; (Suppl 32):321.

56. Wainwright C, Carlin J, Cooper P, et al. Australasian cystic fibrosis BAL study interim analysis. Pediatr Pulmonol. 2006; (Suppl 29):317.

57. Steinkamp G, Tummler B, Malottke R, et al. Treatment of Pseudomonas aeruginosa colonisation in cystic fibrosis. Arch Dis Child. 1989; 64(7):1022-1028. [PubMed: 2517000]

58. Kesser KC, Geller DE. New aerosol delivery devices for cystic fibrosis. Respir Care. 2009; 54(6): 754-767. [PubMed: 19467162] 
59. Mallol J, Rattray S, Walker G, et al. Aerosol deposition in infants with cystic fibrosis. Pediatr Pulmonol. 1996; 21(5):276-281. [PubMed: 8726152]

60. Chua HL, Collis GG, Newbury AM, et al. The influence of age on aerosol deposition in children with cystic fibrosis. Eur Respir J. 1994; 7(12):2185-2191. [PubMed: 7713202]

61. Weber A, Smith A, Williams-Warren J, et al. Nebulizer delivery of tobramycin to the lower respiratory tract. Pediatr Pulmonol. 1994; 17(5):331-339. [PubMed: 8058428]

62. Eisenberg J, Pepe M, Williams-Warren J, et al. A comparison of peak sputum tobramycin concentration in patients with cystic fibrosis using jet and ultrasonic nebulizer systems. Aerosolized Tobramycin Study Group. Chest. 1997; 111(4):955-962. [PubMed: 9106575]

63. Weber A, Morlin G, Cohen M, et al. Effect of nebulizer type and antibiotic concentration on device performance. Pediatr Pulmonol. 1997; 23(4):249-260. [PubMed: 9141110]

64. Mendelman PM, Smith AL, Levy J, et al. Aminoglycoside penetration, inactivation, and efficacy in cystic fibrosis sputum. Am Rev Respir Dis. 1985; 132(4):761-765. [PubMed: 3931522]

65. Heijerman H, Westerman E, Conway S, et al. Inhaled medication and inhalation devices for lung disease in patients with cystic fibrosis: A European consensus. J Cyst Fibros. 2009; 8(5):295-315. [PubMed: 19559658]

66. Steinkamp G, Tummler B, Gappa M, et al. Long-term tobramycin aerosol therapy in cystic fibrosis. Pediatr Pulmonol. 1989; 6(2):91-98. [PubMed: 2494640]

67. FitzSimmons SC. The changing epidemiology of cystic fibrosis. J Pediatr. 1993; 122(1):1-9. [PubMed: 8419592]

68. Konstan MW, Morgan WJ, Butler SM, et al. Risk factors for rate of decline in forced expiratory volume in one second in children and adolescents with cystic fibrosis. J Pediatr. 2007; 151(2):134139. 139. [PubMed: 17643762]

69. McPhail GL, Acton JD, Fenchel MC, et al. Improvements in lung function outcomes in children with cystic fibrosis are associated with better nutrition, fewer chronic Pseudomonas aeruginosa infections, and dornase alfa use. J Pediatr. 2008; 153(6):752-757. [PubMed: 18760423]

70. Nilsson E, Larsson A, Olesen HV, et al. Good effect of IgY against Pseudomonas aeruginosa infections in cystic fibrosis patients. Pediatr Pulmonol. 2008; 43(9):892-899. [PubMed: 18680179]

71. Johansen HK, Gotzsche PC. Vaccines for preventing infection with Pseudomonas aeruginosa in cystic fibrosis. Cochrane Database Syst Rev. 2008; (4):CD001399. [PubMed: 18843616]

72. Ratjen F, Munck A, Kho P, et al. Treatment of early Pseudomonas aeruginosa infection in patients with cystic fibrosis: the ELITE trial. Thorax. 2010; 65:286-291. [PubMed: 19996339] 


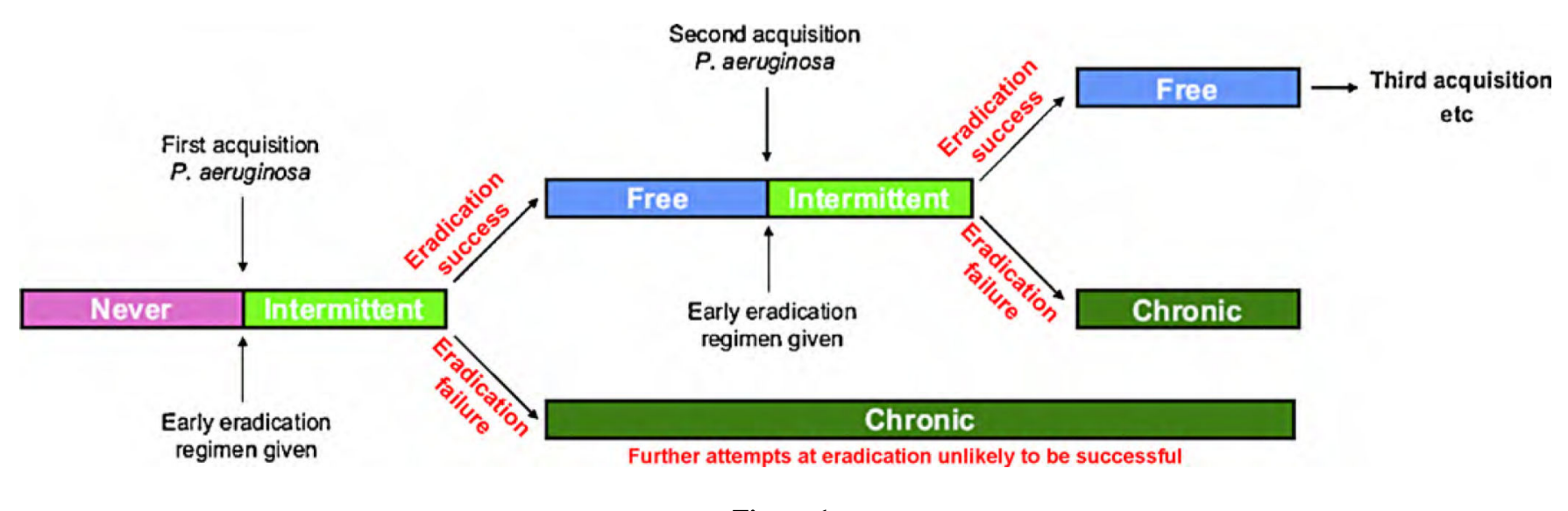

Figure 1.

Illustration of the time course of Pseudomonas aeruginosa infection in patients with cystic fibrosis using Leeds definition of infection and colonization ${ }^{36}$. Taken with permission from $\mathrm{Lee}^{3}$. 


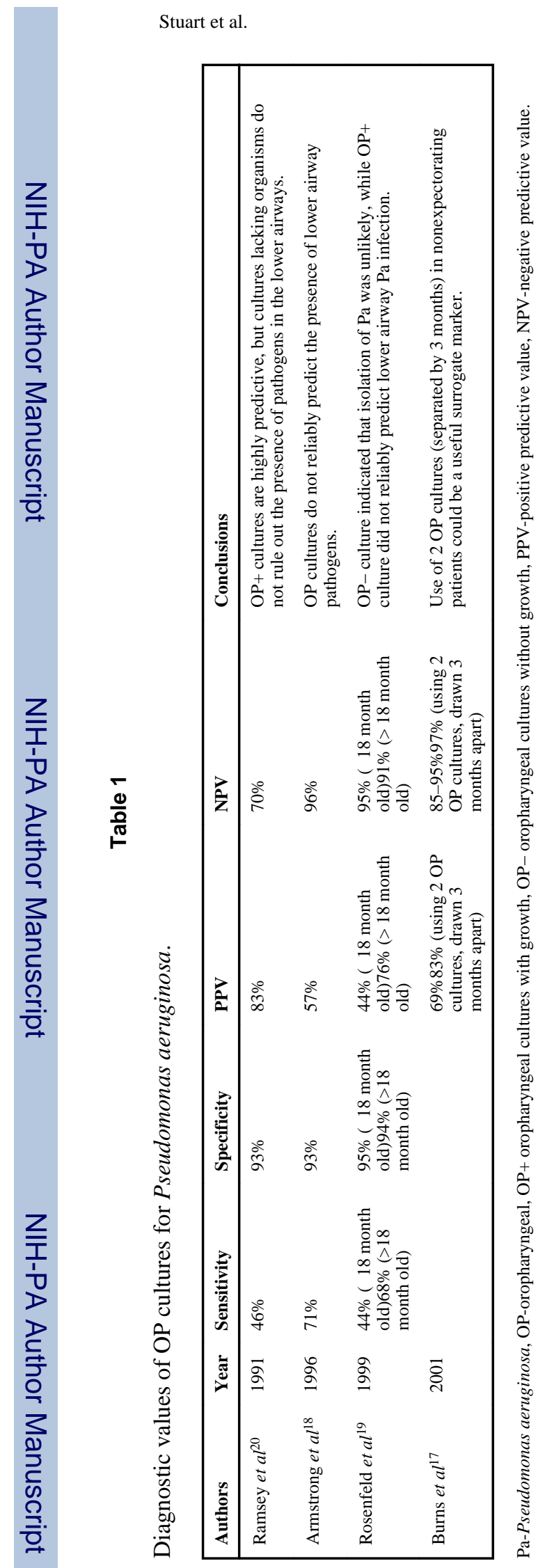

Page 15 


\section{Table 2}

Classification of Pseudomonas aeruginosa Infection

\begin{tabular}{|llll|}
\hline & Copenhagen & Leeds $^{\mathbf{3 4}}$ & European Consensus $^{\mathbf{2 1}}$ \\
\hline Chronic infection & $\begin{array}{l}\text { 6 consecutive monthly sputum } \\
\text { samples with growth of Pa, or a } \\
\text { rise in Pa-specific antibodies }\end{array}$ & $\begin{array}{l}\text { Pa cultures were positive in 50\% or more } \\
\text { of the } 12 \text { months }\end{array}$ & $\begin{array}{l}\text { Presence of Pa for at least } 6 \text { months, } \\
\text { based on } 3 \text { positive cultures at least } \\
1 \text { month apart }\end{array}$ \\
Intermittent infection & $\begin{array}{l}\text { At least 1 isolate of Pa with } \\
\text { normal Pa antibody levels }\end{array}$ & $\begin{array}{l}\text { Pa cultures were positive in 50\% or less } \\
\text { of the } 12 \text { months }\end{array}$ \\
Free of infection & $\begin{array}{l}\text { No growth of Pa during the previous } 12 \\
\text { months, having had a previous Pa } \\
\text { positive culture }\end{array}$ \\
Never & $\begin{array}{l}\text { Pa never cultured from sputum or cough } \\
\text { swab }\end{array}$ & \\
\hline
\end{tabular}

Pa-Pseudomonas aeruginosa 


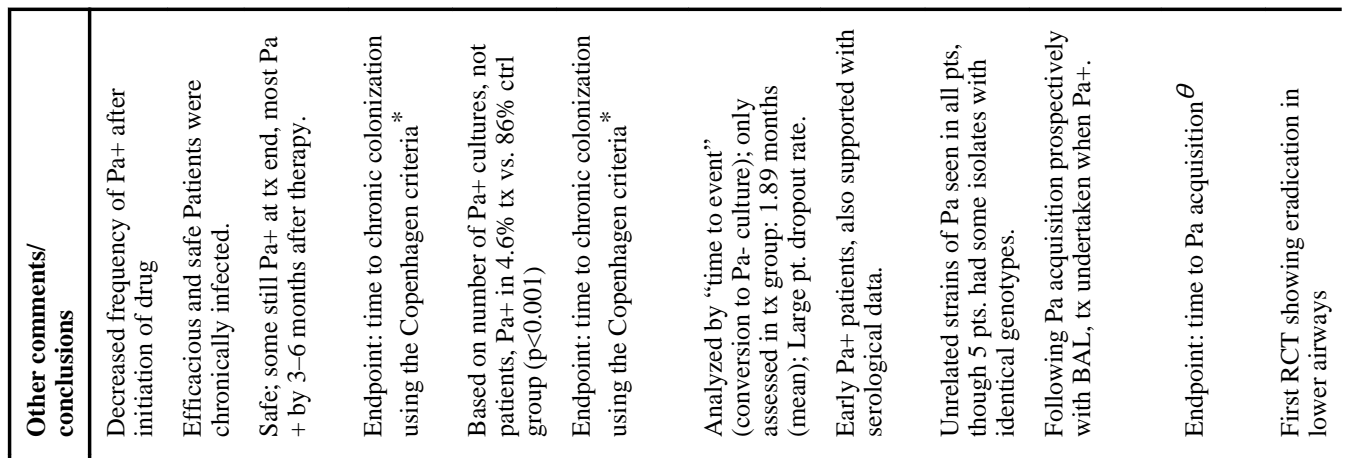

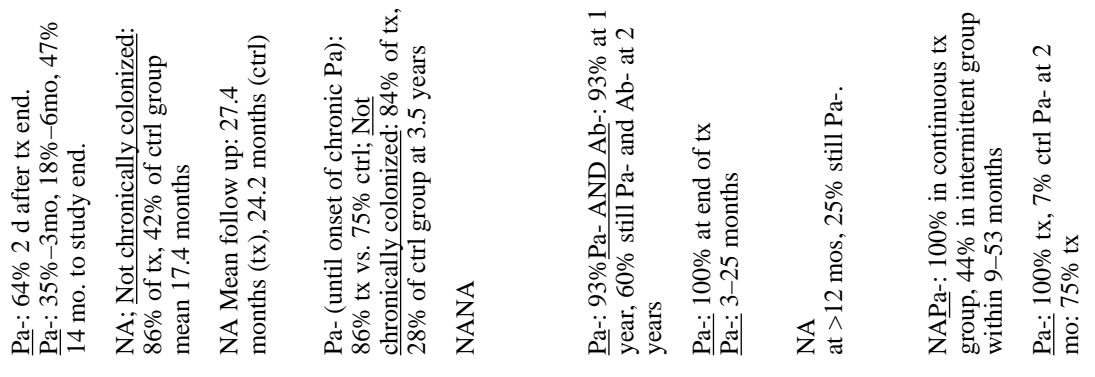
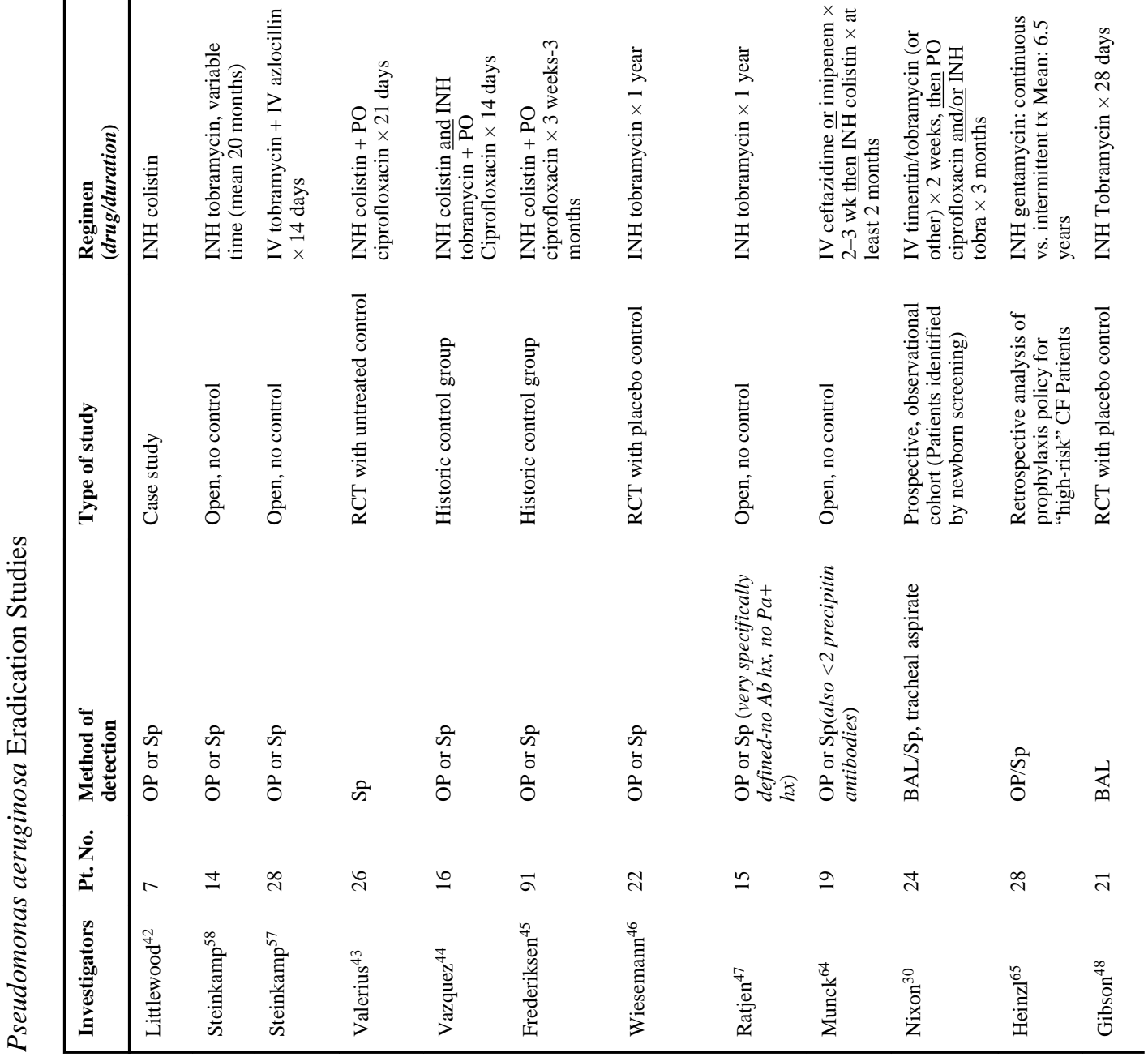

Paediatr Respir Rev. Author manuscript; available in PMC 2014 April 28. 


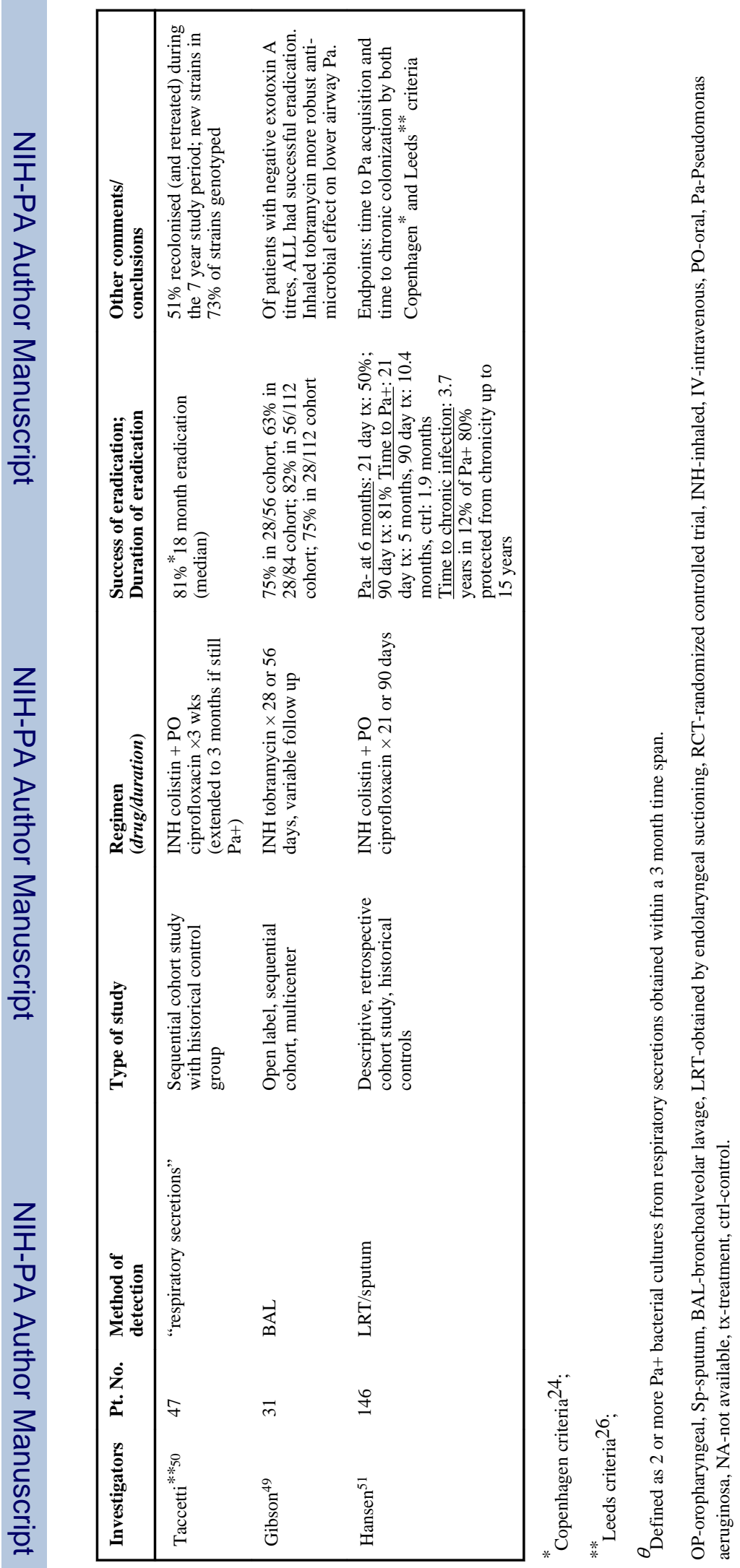

Paediatr Respir Rev. Author manuscript; available in PMC 2014 April 28. 


\section{Table 4}

\section{Ongoing Studies of Pseudomonas aeruginosa Eradication}

\begin{tabular}{|c|c|c|c|c|}
\hline Investigators & No. Pts. & Type of study & Treatment Arms & Preliminary Results \\
\hline ELITE (European) & 88 & Multicenter, Open-label, RCT & $\begin{array}{l}\text { INH tobramycin } \times 28 \text { or } \\
56 \text { days }\end{array}$ & $\begin{array}{l}\sim 90 \% \text { eradication in both groups } 1 \\
\text { mo after end of treatment } \\
\text { (conference presentation) - } \\
\text { awaiting publication }\end{array}$ \\
\hline Ratjen et a ${ }^{53}$ & & $\begin{array}{l}\text { Primary endpoint: median time to } \\
\text { recurrence of } \mathrm{Pa}\end{array}$ & & \\
\hline EPIC (US) & 306 & Multicenter, RCT & $\begin{array}{l}\text { INH tobramycin } \times 28 \\
\text { days }+ \text { PO ciprofloxacin } \times \\
14 \text { days }\end{array}$ & $\begin{array}{l}\text { Preliminary results show all } \\
\text { approaches are effective; the } \\
\text { addition of ciprofloxacin does not } \\
\text { appear to add any benefit } \\
\text { (conference presentation)- } \\
\text { awaiting publication }\end{array}$ \\
\hline Treggiari et al ${ }^{54}$ & & $\begin{array}{l}\text { Cycled therapy based on first } \mathrm{Pa}+ \\
\text { culture versus culture-based therapy } \\
\text { after initial treatment }\end{array}$ & $\begin{array}{l}\text { OR } \\
\text { PO placebo } \times 14 \text { days }\end{array}$ & \\
\hline Belgian Study & $\begin{array}{l}50,32 \\
\text { analyzed } \\
\text { thus far }\end{array}$ & Single centre, RCT & $\begin{array}{l}\text { INH tobramycin } \times 28 \\
\text { days }\end{array}$ & $\begin{array}{l}\text { Initial Pa clearance in } 82 \% \text { in } \\
\text { patients on INH tobramycin, } 93 \% \\
\text { on colisitin+ciprofloxacin; } 41 \% \text { on } \\
\text { INH tobramycin and } 46 \% \text { on } \\
\text { colistin+ciprofloxacin remained } \\
\text { Pa- at } 6 \text { months }\end{array}$ \\
\hline Proesmans et al ${ }^{55}$ & & $\begin{array}{l}\text { Comparison of two antibiotic } \\
\text { regimens in patients with new } \mathrm{Pa}+ \\
\text { cultures }\end{array}$ & $\begin{array}{l}\text { OR } \\
\text { INH colisitin }+\mathrm{PO} \\
\text { ciprofloxacin } \times 3 \text { months }\end{array}$ & \\
\hline Australasian BAL & 168 infants & Multicenter, Prospective, RCT & $\begin{array}{l}\text { IV tobramycin +timentin } \\
\text { or ceftazidime, followed } \\
\text { by }\end{array}$ & $\begin{array}{l}100 \% \text { eradication in all pts } \\
\text { followed for } 2 \text { years thus far, } \\
\text { regardless of BAL or cough } \\
\text { suction as culture source }\end{array}$ \\
\hline Wainwright et $\mathrm{al}^{56}$ & & $\begin{array}{l}\text { Evaluation of BAL versus non-BAL } \\
\text { directed therapy }\end{array}$ & $\begin{array}{l}\text { INH tobramycin } \times 2 \\
\text { months }+\mathrm{PO} \\
\text { ciprofloxacin } \times 1 \text { month }\end{array}$ & \\
\hline
\end{tabular}

RCT-randomized controlled trial; Pa-Pseudomonas aeruginosa, Pa+-Pa positive culture, Pa- -Pa negative culture, BAL-bronchoalveolar lavage, INH-inhaled, PO-oral. 